\title{
Evolving Experience in The Management of Empyema Thoracis
}

\author{
K Shrestha, S Shah, S Shrestha, S Thulung, B Karki, DP Pokhrel
}

Department of Cardiothoracic and Vascular Surgery Bir Hospital, National Academy of Medical Sciences, Kathmandu, Nepal

Corresponding Author

Dr Kiran Shrestha

Department Cardiothoracic and Vascular Surgery Unit, Bir Hospital, NAMS

Kathmandu, Nepal

E-mail: shresthakp8@yahoo.com

Citation

K Shrestha, S Shah, S Shrestha, S Thulung, B Karki, DP Pokhrel. Evolving experience in the management of Empyema Thoracis. Kathmandu Univ Med J 2011;33(1)5-7.

\begin{abstract}
Background

Empyema thoracis a disease of significant morbidity and mortality, especially in the developing world. However, the optimal management of empyema thoracis remains controversial.
\end{abstract}

\section{Objective}

To analyse evolving experience in clinical presentation, management, outcome and factors contributing to adverse morbidity in empyema thoracis.

\section{Methods}

This is hospital based retrospective study of patients who were diagnosed with empyema thoracis in cardiothoracic and vascular surgery (CTVS) unit, Bir Hospital, Kathmandu, Nepal over a period of one year (July 2009 to June 2010). A total of forty-six adult cases were categorized into two treatment groups: (i) thoracotomy for decortication (ii) segmentectomy, lobectomy and redo-thoracotomy for pneumonectomy. The median duration of illness prior to hospital admission was compared. The presence of loculated pleural fluid determined the need for thoracotomy.

\section{Results}

Out of forty-six cases, twenty- nine (63.04\%) who had early thoracotomy ( $<22$ days) had prompt symptomatic recovery. Forteen out of seventeen (82.35\%) of the patients who were initially treated with thoracocentesis or tube thoracostomy eventually needed thoracotomy. There was a positive shift in management towards early thoracotomy resulting in prompt symptomatic recovery. Significant complications were noted in eight patients who had delayed thoracotomy. Complications included recurrent empyema with lung abscess $(n=3)$, restrictive lung disease $(n=3)$, bronchopleural fistula $(n=1)$ and scoliosis $(n=1)$.

\section{Conclusion}

Early thoracotomy and decortication was found to be an excellent surgical procedure with good functional results and high patient satisfaction rate.

\section{KEY WORDS}

empyema, thoracotomy, complications

\section{INTRODUCTION}

Empyema thoracis has been recognised since the time of the Hippocrates but the optimal treatment remains controversial. ${ }^{1-6}$ As early as 1875 , Gotthard Biilau advocated closed water seal drainage for empyema. ${ }^{7}$ Berger et al, however, suggested that immediate drainage was not required for all patients with complicated parapneumonic effusions. ${ }^{8}$ Fishman et al advised early decortication only in unusual circumstances, for example, in immunosuppressed patients and not as a primary treatment. ${ }^{9}$ There is, thus, a tendency to persevere with antibiotics, thoracentesis, and closed intercostal tube drainage and a general reluctance to refer patients with empyema early for operative surgical management.
Despite the ready availability of broad-spectrum antimicrobial agents, empyema thoracis remains a significant problem. ${ }^{10}$ The optimal management remains controversial, with advocates for a variety of treatment options, which include antibiotics alone or in combination with thoracocentesis, tube thoracostomy, fibrinolytics, thoracoscopy, minithoracotomy, and debridement or decortication. ${ }^{11-14}$ Therapeutic decisions are compounded by a variety of factors, which include the disease spectrum, virulence of the infecting organism, host resistance, accurate determination of the duration/stage of the illness and timing of appropriate intervention. 
The present study is hence designed to evaluate evolving experience in the diagnosis and definitive management of empyema in an effort to identify factors contributing to morbidity.

\section{METHODS}

\section{Study design}

This study was a retrospective analysis of all adult cases of empyema thoracis admitted in the Cardiothoracic and Vascular surgery (CTVS) unit of Bir Hospital, a tertiary care teaching hospital in Kathmandu, Nepal over a period of 12 months (July 2009-June 2010).

Empyema thoracis was defined as pleural effusion with the presence of frank pus on pleural aspiration.

\section{Exclusion criteria}

(1) Age less than 16 years;

(2) Empyema thoracis secondary to any surgical procedure.

Among forty-six consecutive patients, 38 were men and 8 women, with age range from 16 to 74 years. They were divided into two groups, one group (group $1, n=29$ ) consisted of patients who had undergone thoracotomy for decortication; and the other (group 2, $n=17$ ) consisted of those who had undergone segmentectomy, lobectomy and redo-thoracotomy for pneumonectomy. The reason for segmentectomy, lobectomy and redo-thoracotomy were considered with respect to their duration of operation from the initial presentation. Data pertaining to mode of presentation, diagnosis, definitive management and complications (if any) were also analysed.

Ultrasound scan (USG) of the chest was performed and information concerning loculation, fluid density and thickness of the pyogenic membrane was documented. CT scan was performed in cases where an underlying disorder of the lung was suspected. The presence of loculated pleural fluid as shown by ultrasonogram or CT scan of the chest determined the need for thoracotomy.

The statistical signfcance was defined as $p$ value $<0.05$. Analysis was carried out using MS Excel, SPSS software, version 11.5 (SOSS, Inc., Chicago, Illinois).

\section{RESULT}

The median duration of development of symptoms prior to surgery was 22 days (range 07-38 days, $n=29$ ) for the patients consisted of patients who had undergone thoracotomy for decortication (group 1) while the median duration of the development of symptoms prior to admission and operation was 42 days (range 18-90 days, $\mathrm{n}=17$ ) for the patients who had undergone segmentectomy, lobectomy and redo-thoracotomy for pneumonectomy (group 2).

Fever, cough, chest pain and dyspnoea were the most common symptoms

In this study, Fourteen out of 17 (82.35\%) of the patients who were initially treated with thoracocentesis or tube thoracostomy eventually required thoracotomy for segmentectomy, lobectomy and redo-thoracotomy for pneumonectomy. These included recurrent empyema with lung abscess $(n=3)$, restrictive lung disease $(n=3)$, bronchopleural fistula $(n=1)$ and scoliosis $(n=1)$.

\section{DISCUSSION}

Empyema thoracis is defined as the presence of pus in the pleural cavity. Frank purulence must develop before an effusion is termed an empyema. The empyema may initially lie free in the pleural space but soon becomes encapsulated by fibrinous pleural adhesions. The pus becomes more viscous as fluid is absorbed. Fibrin is continually deposited on the pleural surfaces producing a thickened peel that can form as early as seven to 10 days after the onset of the parapneumonic effusion. ${ }^{15}$ Adequate treatment at this stage usually allows full re-expansion of the lung with no functional impairment. The time of transition from acute to chronic empyema is arbitrary. Experimental animal models of empyema loculate within three days of bacterial invasion with fibroblast invasion evident at five days. ${ }^{16}$ The free pleural fluid from the pleural space is easily drained before the deposition of intrapleural fibrin. As the empyema becomes chronic, however, continuing fibrosis promotes restriction of movement of the chest wall and diphragm leading eventually to a shrunken, immobile hemithorax with crowding of the ribs and scoliosis. Some permanent functional impairment follows even if lung re-expansion is achieved Considerable debate is therefore focused on the ideal management of empyema thoracis. Many authors suggest that the majority of patients with empyema can be adequately treated by tube drainage and antibiotics. ${ }^{17}$ However, in our study, fourteen out of 17 (82.35\%) of the patients who were initially treated with chest drainage required thoracotomy and for decortication.

Although this study was retrospective and nonrandomized, complications were clearly evident in patients in whom surgery was delayed. Empyema thoracis is a dynamic progressive condition that has been described in three pathological stages: exudative, fibropurulent and organized. ${ }^{18}$ Large case-controlled studies are required to define the place of thoracoscopy in the definitive management of empyema. Given the limitations of all treatment modalities, prospective studies are required to develop evidence-based care pathways. In addition, prospective studies to define the effectiveness of open tube thoracostomy in different stage of empyema have to be conducted. 


\section{CONCLUSION}

In our study, early thoracotomy and decortication was found to be an excellent surgical procedure. Functional results were also outstanding and the patients returned to normal activities that they have been performing before surgery. The post-operative results are also affected by

\section{REFERENCES}

1. Hippocrates. Genuine works of Hippocrates. Translated by Anderer F. London: Sydenham Society, 1847.

2. Kerr A, Vasudevan VP, Poerll S, Ligenza C. Percutaneous catheter drainage for acute empyema. Improved cure rate using CAT scan, fluoroscopy, and pigtail drainage catheters. NY State J Med 1991;91:47.

3. Ridley PD, Braimbridge MV. Thoracoscopic debridement and pleural irrigation in the management of empyema thoracis. Ann Thorac Surg 1991;51:461-4

4. Hoff SJ, Neblett WW, Heller RM, Pietsch JB, Holcomb GW Jr, Sheller JR, et al. Postpneumonic empyema in childhood: selecting appropriate therapy. J Paediatr Surg 1989;24:659-64.

5. Lee KS, Im JG, Kim YH, Hwang SH, Bae Wk, Lee BH. Treatment of thoracic multiloculated empyemas with intracavity urokinase: a prospective study. Radiology 1991;179:771-5.

6. Aye RW, Froese DP, Hill LD. Use of purified streptokinase in empyema and haemothorax. Am J Surg 1991;161:560-2.

7. Meyer JA. Gotthard Bulau and closed water-seal drainage for empyema, 1875-1891. Ann Thorac Surg 1989; 48:597-9.

8. Berger HA, Morganroth ML. Immediate drainage is not required for all patients with complicated parapneumonic effusions. Chest 1990;97:731-5.

9. Fishman NH, Ellerston DG. Early pleural decortication for thoracic empyema in immunosuppressed patients. J Thorac Cardiovasc Surg 1977; 74:537-41. the time duration between development of the symptoms and the time of surgery. Further prospective studies, should also be conducted to explore the benefits of tube tube thoracostomy in the early management of empyema thoracis and eliminate any confounding factors that might have existed.

10. Luh SP, Chou MC, Wang LS, Chen JY, Tsai TP. Video-assisted thoracoscopic surgery in the treatment of complicated parapneumonic effusions or empyemas. Chest 2005 Apr;127(4):1427-32.

11. Soriano T, Alegre J, Alemán C, Ruiz E, Vázquez A, Carrasco JL, et al. Factors influencing length of hospital stay in patients with bacterial pleural effusion. Respiration 2005;72(6):587-93.

12. Kearney SE, Davies CW, Davies RJ, Gleeson FV. Computed tomography and ultrasound in parapneumonic effusions and empyema. Clin Radiol. 2000 Jul;55(7):542-7.

13. Malhotra P, Aggarwal AN, Agarwal R, Ray P, Gupta D, Jindal SK Clinical characteristics and outcomes of empyema thoracis in 117 patients: a comparative analysis of tuberculous vs. non-tuberculous aetiologies. Respir Med 2007 Mar; 101(3):423-30.

14. Ben-Or S, Feins RH, Veeramachaneni NK, Haithcock BE. Effectiveness and risks associated with intrapleural alteplase by means of tube thoracostomy. Ann Thoracic Surg 2011 Mar;91(3):860-3.

15. DeMeester TR, Lafontaine E. The Pleura. In: Sabiston DC Jr, Spencer FC, eds. Surgery of the chest. 5th ed. Philadelphia: Saunders, 1990.

16. Strange C, Tomlinson JR, Wilson C, Harley R, Miller KS, Sahn SA. The histology of experimental pleural injury with tetracycline, empyema and carrageenan. Exp Mol Pathol 1989;51:205-19.

17. Odelowo EO, Adedoyin MA, Andy JJ, Olamijulo SK. Empyema thoracis in Nigerians: experience with a policy of conservative operative management. Int Surg 1989; 74: 247-52.

18. American Thoracic Society.. Management of nontuberculous empyema. Am Rev Respir Dis 1962; 85: 935-6. 